\title{
Способствует ли решению проблем расселения Стратегия пространственного развития РФ?
}

\author{
Л.Я.Герцберг, ЦНИИП Минстроя России, Москва
}

В статье подчёркивается важность и своевременность разработки Схемы пространственного развития Российской Федерации (СПРР) до 2025 года в согласовании социальноэкономического и территориального планирования и отмечаются основные недостатки проекта СПРР, прежде всего: декларативный характер, отсутствие связи с бюджетным прогнозированием несмотря на относительно небольшой (шестилетний) прогнозный срок проекта, недостаточная разработанность механизмов реализации. Приведённые в проекте основные направления совершенствования расселения рассчитаны на долгосрочную перспективу, ожидаемые результаты на шестилетний срок не конкретизированы. Вопреки заявленному в проекте важнейшему постулату - предотвращение процессов сверхконцентрации населения, обезлюдивания Сибири и Дальнего Востока, сельских территорий - основная ставка делается на развитие агломераций, крупнейших и крупных городов, в которых планируется проживание подавляющей части населения, при этом не учитывается, что процессы сжатия пространства имеют место и внутри агломераций. В среднем от 60 до 80\% населения, производственных фондов концентрируются в ядрах агломераций, что приводит к ухудшению экологической ситуации, снижению качества городской среды, увеличению продолжительности поездок населения и другим негативным явлениям. Требует обоснования целесообразность создания макрорегионов. Можно ожидать, что в условиях приоритетного экономического развития, концентрации бюджетных средств в макрорегионах с целью реализации мегапроектов увеличится дистанция между депрессивными территориями и финансовыми ресурсами, что будет способствовать дальнейшему развитию процессов опустынивания территории. Ставка на развитие магистральный сетей в проекте СПРР - важный шаг в обеспечении связности территории, однако для решения проблем стабилизации сельского расселения не менее важным является развитие сети местных благоустроенных дорог, в том числе с привлечением федеральных средств. Предлагаемые механизмы реализации основных направлений совершенствования расселения не новы и в прошлом не дали ожидаемых результатов. Общий вывод - ожидаемая эффективность стратегии в плане создания предпосылок для решения актуальных проблем расселения - крайне низкая.

Ключевые слова: социальное и экономическое планирование, территориальное планирование, бюджетный прогноз, расселение населения, процессы супер концентрации, городская политика, экологическая ситуация агломерации, макрорегионы, сельские поселения, механизмы реализации, эффективность стратегии пространственного развития.

Does the spatial development strategy contribute to solution the problems of settlements?

L.Ya.Gertsberg, Central Institute for Research and Design of the Ministry of Construction and Housing and Communal Services of the Russian Federation, Moscow

The article underlines the importance of territorial scheme of the Russian Federation until 2025 year in the coordination of social and economic planning. However, the following disadvantages are emphasized: declarative character, lack of communication with the budget forecasting, insufficient development of the implementation mechanisms. The main directions of the population settlement improvement are defined for the long term; the 6-year period expected results are not given. Contrary to the most important postulate declared in the project to prevent the super concentration processes and the migration of people from Siberia and Far East, further development of the agglomerations of the big and biggest cities is envisaged. It should be taken into account that in Russia from 60 to $80 \%$ of the population, production facilities are concentrated in the cores of agglomerations, which leads to a deterioration of the ecological situation, a decrease in the quality of the urban environment, an increase in the duration of commotions for the population, and other negative phenomena. It can be expected when the economic development is the priority and the budgetary funds are concentrated in macro- regions with the aim of implementing mega-projects, the distance between depressive territories, and financial resources will increase. It will contribute to the further development of the desertification processes in the depressive territory. The emphasis on the development of magistral networks in the scheme project is the important step in ensuring the connectivity of the territory, but to solve the problems of the rural settlements stabilization, it is important to develop a network of thelocal well-maintained roads, with the involvement of federal funds. The general conclusion is that the expected effectiveness of the strategy in terms of creating the prerequisites for solution of the actual problems of the settlements is extremely low.

Keywords: social and economic planning, territorial planning, budget forecasting, population resettlement, 
super concentration processes, urban policy, ecological situation, agglomerations, macro-regions, rural settlements, implementation mechanisms, effectiveness of the spatial development strategy.

Анализу проблем расселения в России посвящено много исследований $[1 ; 2]$, поэтому отметим только основные проблемы: сжатие пространства расселения населения, поддерживаемое рыночными тенденциями и государственной политикой сжатия экономического пространства и, как следствие, опустынивание значительных территорий, разрушение опорного каркаса сельского расселения; исчезновение сельских населённых пунктов, чрезвычайно высокий современный уровень и продолжающиеся тенденции концентрации населения в Московской агломерации; низкое качество среды проживания в городских и сельских поселениях, крайне неблагоприятная экологическая ситуация во многих городах. 0 масштабах экологической проблемы свидетельствуют данные, приведённые на III Невском экологическом конгрессе в России (14-15 мая 2010 года): «в неблагоприятной природной среде проживают как минимум 40 миллионов человек, из них 1 миллион живёт в условиях, представляющих собой опасный уровень загрязнения». Усиливается негативное влияние экологического фактора на состояние здоровья населения, что приводит к росту социальной напряжённости в регионах [3]. В проекте стратегии пространственного развития (СПРР) приводятся другие, но тоже достаточно высокие показатели: 15\% городского населения проживает в условиях очень высокого и высокого уровня загрязнения атмосферного воздуха.

Усилению тенденций сжатия пространства расселения способствует значительный разрыв в качестве среды проживания не только на межрегиональном, но и на внутрирегиональном уровнях. Низкое качество среды проживания большинства городов является одной из важнейших причин их неконкурентоспособности в привлечении капитала и высококвалифицированных специалистов, что затрудняет переход к инновационной экономике в условиях развития процессов глобализации.

СПРР призвана способствовать решению этих проблем, увязывая перспективное расселение с размещением производительных сил в рамках одного документа, заменяя, таким образом ранее существовавшие Генеральную схему расселения России и Генеральную схему размещения производительных сил России.

СПРР разрабатывается в два этапа: первый - концепция до 2030 года, второй - стратегия до 2025 года. Оба этапа определяют цели и ориентированы на долгосрочную перспективу. Подчёркивая разницу между этими документами, И.В. Шацкая отмечает, что «классики стратегического менеджмента учат нас тому, что стратегия не определяет цели, а имеет отношение к способам их достижения. Кроме того, стратегия имеет дело со среднесрочной перспективой. На долгосрочный период можно сформулировать Концепцию развития, но не стратегию, служащую средством достижения целей, всегда ограниченных временными и ресурсными рамками» [4]. Ограничение временными и ресурсными рамками предполагает, что стратегия должна разрабатываться с учётом бюджетного прогноза до 2025 года.

В соответствии с Постановлением Правительства РФ от 31 августа 2015 г. № 914 «0 бюджетном прогнозе Российской Федерации на долгосрочный период» бюджетный прогноз Российской Федерации разрабатывается на 18-летний период каждые шесть лет. В 2015 году бюджетный прогноз Российской Федерации разрабатывался на период до 2030 года. В настоящее время разработан проект бюджетного прогноза России до 2034 года. Экспертизу проекта провела Высшая школа экономики; прогнозируется, что бюджетный сектор РФ в ближайшие 18 лет будет развиваться в условиях серьёзных финансовых ограничений. Наиболее сложным будет период 2016-2020 годов, в течение ближайших четырёх лет расходы бюджетной системы в сопоставимых ценах сократятся по сравнению с 2016 годом на 6\%, расходы федерального бюджета - на 16\%. Предусматривается, что в дальнейшем, в период 2020-2034 годов, расходы бюджетной системы в неизменных ценах начнут медленно расти, однако в неизменных ценах в 2034 году все еще будут ниже уровня 2016 года [5].

Несмотря на то, что проект СПРР РФ разрабатывается на период до 2025 года, то есть на шесть лет, он не опирается на существующий бюджетный прогноз, содержит масштабные задачи, общие направления по их реализации, рассчитанные на долгосрочную перспективу. Видимо, по этой причине на заседании Комитета Совета Федерации по экономической политике 12 июля 1918 года (протокол № 154) утверждены следующие рекомендации: при разработке стратегии исходить из определения горизонтов стратегического планирования до 2035 года и стратегического видения до 2050 года. Очевидно, что точность стратегического прогнозирования и ответственность за его качество тем меньше, чем больше период, на который разрабатывается стратегия.

В отсутствие ресурсного обоснования многие положения проекта СПРР носят декларативный характер. В концепции отмечено, что «в рамках разработки СПРР для каждого этапа должны быть определены основные задачи и целевые показатели реализации по различным направлениям пространственного развития страны». На среднесрочный период они не определены, но есть видение пространственного развития России на долгосрочную перспективу, которое базируется на важнейшем постулате «фундаментального, навечного, а не временного освоения, развития территории, то есть, в конечном счёте, нацеливающего на последовательное, упорное и трудоёмкое её преобразование, а не на истощение, обеспечение сбалансированности пространственного развития путём предотвращения процессов сверхконцентрации, содействия выращиванию новых пространств роста, предотвращения обезлюдивания Сибири и Дальнего Востока, сельских территорий, инфраструктурного обеспечения пространственного развития экономики и социальной сферы». 
Определённая в Концепции и Стратегии государственная политика в области расселения, направленная на развитие крупных городских агломераций и сетевых кластеров, не корреспондирует с новым видением России «В проекте СПРР в приоритеты пространственного развития включено социально-экономическое развитие крупнейших и крупных городских агломераций. В концепции предусматривается развитие надагломерационных пространств - сетевых кластеров, объединяющих от пяти-десяти до 20 и более агломераций, которые могут образовать 10-15 относительно компактных макрорегионов с суммарным демографическим потенциалом в 75-85 млн человек и экономическим потенциалом, существенно превышающим суммарный потенциал входящих в их состав муниципальных образований. В проекте СПРР в приоритетное направление совершенствования расселения также включено социально-экономическое развитие городов с численностью населения от 100 тыс. до 500 тыс. человек, формирующих опорный каркас расселения малых и средних городов, сельских территорий за пределами крупнейших и крупных городских агломераций, обеспечивающих повышение устойчивости системы расселения Российской Федерации. В условиях ограниченных финансовых и трудовых ресурсов приходится выбирать приоритеты, и таким приоритетом для государства и регионов в последние десятилетия являлось развитие агломераций.

Но при этом надо иметь ввиду, что существуют пределы концентрации экономики и расселения, при их превышении наблюдается негативный эффект [7].

0собенность развития агломераций в РФ - концентрация большей части населения агломераций (от 60 до 80\%) в их ядре, площадь которого в среднем не превышает 10-15\% общей площади агломерации. Результатом являются чрезмерные нагрузки на природный комплекс, ухудшение экологической ситуации, снижение качества жизни населения. В районной планировке в целях ограничения концентрации населения использовался показатель демографической ёмкости территорий. В развитых странах с целью снижения чрезмерных нагрузок на ядра агломераций проводится государственная политика стимулирования процессов полицентрического развития агломераций. Модель сетевого полицентрического развития близка к групповой системе расселения, которая рассматривалась как основная в первой генеральной схеме расселения СССР. Эта модель обеспечивает экономический эффект за счёт сокращения нерациональных транспортных перевозок и передвижений населения, кооперированного использования инфраструктуры, социальный эффект - за счёт снижения потерь времени населением на ежедневные поездки к местам приложения труда, снижения транспортной усталости, сокращения разрыва в уровне социально-экономического развития поселений, расположенных в центре и на периферии сетевых структур, экологический эффект - за счёт снижения нагрузок на природный комплекс, снижения загрязнённости среды при более равномерном расселении населения и размещении производства на территории агломерации. В Стратегии декларируется целесообразность развития крупных и крупнейших агломераций, но при этом не указывается на необходимость их полицентрического развития за счёт активного формирования в пределах агломераций сети городов-центров с развитой социальной, производственной инфраструктурой, обеспечивающих сдерживание центростремительных тенденций и создающих более равномерные нагрузки на территории.

В Концепции СПРР отмечается, что «целевые установки перехода к инновационному развитию, принятые в Стратегии-2020, сохраняют свою актуальность, однако кардинально изменившиеся условия привлечения финансовых и технологических ресурсов, ориентация на импортозамещение меняют оценки конкурентоспособности регионов относительно созданного и используемого потенциала инновационного развития, о чём свидетельствует выдвижение на передовые позиции в условиях кризиса регионов с высокой долей военно-промышленного комплекса в структуре производства, что даёт основание предполагать, что эти регионы в будущем могут стать центрами генерации и реализации инноваций». Изменения в оценке конкурентоспособности регионов не нашли отражения в проекте СПРР.

В условиях развития глобализации проблема повышения конкурентоспособности территорий чрезвычайно актуальна. Современная концепция конкурентоспособного города включает следующие характеристики: экологичный город (зелёная экономика, использование возобновляемых источников энергии, сохранение природных ландшафтов и т.д.); устойчивый город (эффективное использование природных ресурсов, сохранение их для жизни будущих поколений); безопасный город (защищённый от природных катаклизмов и т.д.); умный город, использующий передовые технологии в городском хозяйстве; эстетически привлекательный город (высокие художественные качества застройки, наличие памятников архитектуры, уникальных объектов и др.); глобальный город, включённый в мировую экономику. Конечно, понятие конкурентоспособности территории не исчерпывается факторами, на которые можно влиять средствами эффективной пространственной организации территории, не менее важную роль играют политическая ситуация, бизнес-климат, но тем не менее градостроительными средствами создаются важные предпосылки для повышения инвестиционной и миграционной привлекательности территорий.

Проект СПРР ориентируется на опыт разработки Генеральной схемы пространственного размещения производительных сил, в составе которой были выделены 18 экономических районов на начало 1975 года [8]. Экономический район представлял цельную в экономическом отношении часть страны, в основе которой лежал территориально-производственный комплекс (ТПК), характеризующийся определённым сочетанием отраслей производства, разносторонними связями между ними, общностью экономико-географического по- 
ложения и исторического прошлого, обеспечивающими общегосударственную специализацию данного района в территориальном разделении труда. Сетка экономических районов была утверждена в 1963 году и уточнена в 1966 году. В разрезе экономических районов были разработаны предложения по размещению производительных сил. Огромная площадь экономических районов не исключала необходимости разработки региональных схем размещения производительных сил. Однако в период существования СССР такие схемы не разрабатывались, но они начали проектироваться в период рыночной экономики [9] для Свердловской, Воронежской, Пермская областей, для Москвы. Цель этих схем состояла в создании инструмента государственного регулирования пространственного развития рыночной экономики. В период становления рыночной экономики ТПК как основа формирования экономических районов перестали существовать, «экономический район» не использовался в практике государственного регулирования экономического развития.

В проекте СПРР предложено выделять 14 макрорегионов с целью обеспечения условий для развития регионального взаимодействия. Макрорегионы выделяются по принципу территориальной общности, соседского местоположения, наличию значительного потенциала межрегионального взаимодействия, кооперации в рамках специализации входящих в их состав регионов, наличию крупных центров экономического роста (или возможности их создания), наличию объектов транспортной, энергетической, информационно-коммуникационной инфраструктур, обеспечивающих связанность субъектов Российской Федерации, входящих в макрорегион, наличию (или возможности создания) объектов отраслей социальной сферы федерального значения, способствующих повышению транспортной доступности для оказания услуг указанных отраслей в пределах макрорегиона. На макрорегионы планируется разрабатывать стратегии социально-экономического развития и территориальные программы социально-экономического развития. По сравнению с Концепцией, где макрорегионы формировались на основе объединения близко расположенных агломераций путём создания надагломерационных пространств, в проекте СПРР макрорегионы привязаны к границам входящих в их состав субъектов РФ, число которых варьирует от трёх до 13. В отличие от экономических районов единой общегосударственной специализации в территориальном разделении труда в макрорегионах нет. Поэтому отрасли эффективной экономической специализации расписаны для каждого субъекта РФ.

Председатель Совета Федерации В.И. Матвиенко на парламентских слушаниях «0 разработке стратегии пространственного развития Российской Федерации» [11] отметила, что «поддержание устойчивости системы расселения должно базироваться, прежде всего, на экономических приоритетах (курсив автора статьи), реализация которых позволит обеспечить создание и обновление инфраструктуры и решить социальные задачи». Концентрация бюджетных средств в макрорегионах в рамках политики приоритетов экономических интересов, поддержки существующих и формирования новых агломераций как локомотивов экономического развития приведёт к дальнейшему вымиранию сёл, разрушению опорного каркаса сельского расселения, расширению новой Москвы. Ожидается, что уже к 2035 году население Москвы превысит 23 млн человек [12].

Необходимо учитывать также и тот факт, что страна развивается в условиях рыночной экономики, примерно 80\% инвестиций в экономику составляют частные инвестиции. По законам рынка бизнес будет развиваться там, где ему будет гарантирована бо́льшая прибыль, попытки регулировать этот процесс на государственном уровне с помощью различного рода преференций далеко не всегда успешны. 06 этом свидетельствует опыт создания особых экономических зон. На основе анализа обширного фактолого-статистического материала о практике задействования 0Э3, 3ТР и ТОР в различных субъектах РФ А. Швецов [13] проанализировал эффективность активно применяемых в последние годы «федеральным центром» инструментов государственного стимулирования территориального развития в рамках концепции «точек роста». Речь идёт об особых экономических зонах», «зонах территориального развития», «территориях опережающего развития», для которых установлен особый правовой режим, для инвесторов предусмотрены налоговые, инфраструктурные и другие льготы. «Выводы не утешительны: “вместо того, чтобы сыграть роль "точек роста" и мощных источников распространения ("диффузии") технологических и других инноваций, анализируемые локальные ареалы за редкими исключениями оказались "черными дырами"- бизнес-анклавами, выключенными из кооперационных связей с окружающим и экономическим пространством и, хуже того, дестимулирующими его развитие, вытягивающими чужие ресурсы, прежде всего высококвалифицированные трудовые"». Причины он видит в общем стандартном подходе к индивидуальным проектам, несогласованности действий государства и бизнеса, отсутствии корректно проведённых предварительных расчётов эффективности и методики выявления пользы для всех заинтересованных сторон (и государства, и региона, и бизнеса), «переходе от замешенного на иждивенчестве "мест" госпатернализма в региональной политике к поощрению саморазвития регионов в условиях федеративного государства».

С учётом вышесказанного представляется, что предусмотренное в проекте СПРР формирование единого инструмента развития территорий в целях унификации требований к созданию и функционированию территорий с особыми преференциальными условиями ведения предпринимательской деятельности не будет способствовать улучшению ситуации с развитием точек роста.

Следует также отметить, что до проекта СПРР была разработана масса федеральных и региональных документов стратегического планирования и государственных программ: 
отраслевые федеральные схемы (развития федерального транспорта, здравоохранения, обороны и безопасности, энергетики, высшего образования), концепция долгосрочного социально-экономического развития РФ до 2020 года, концепция долгосрочного инновационного развития РФ до 2020 года, Стратегия научно-технологического развития Российской Федерации на период до 2035 года. В законе «0 стратегическом планировании» нет упоминания о концепции инновационного развития до 2020 года, стратегии научно-технологического развития до 2035 года, концепции социально-экономического развития до 2020 года. Вместе с тем они не отменены, действуют, разработаны региональные схемы социально-экономического развития, региональные схемы размещения производительных сил, региональные концепции инновационного развития. Всё это подменяется в проекте СПРР рекомендациями для регионов по выделению перспективных отраслей экономической специализации.

При разработке стратегии расселения не нашли отражения многие положения Градостроительной доктрины РФ, разработанной в Российской академии архитектуры и строительных наук под руководством академика Г.В. Есаулова, в частности:

- как перспективное направление совершенствования расселения: укрепление пространственного каркаса системы расселения за счёт развития существующих и создания новых центров местных, межмуниципальных, региональных, межрегиональных; формирование мультимодального транспортно-логистического каркаса системы расселения, обеспечивающего устойчивую пространственную связь центров систем расселения, других городских и сельских населённых пунктов;

- как важный механизмы мониторинга реализации пространственной политики: разработка системы индикаторов, нацеленных на объективное отражение наиболее существенных аспектов градостроительной политики; разработка индикаторов и критериев оценки качества городской среды;

- как важное направление совершенствования институциональной структуры управления градостроительным развитием страны: создание на базе ведущих проектных, научно-исследовательских учреждений градостроительного профиля, в том числе Российской академии архитектуры и строительных наук, системы федеральных центров аналитического, научно-методического и проектного обеспечения разработки и реализации градостроительной политики [14].

Разработка совмещённой схемы размещения производительных сил и расселения населения - прогрессивный шаг в области стратегического планирования. Однако схема затрагивает только федеральный уровень. Реализация программных мероприятий осуществляется на региональном и муниципальном уровнях. За рубежом муниципальному уровню уделяется наибольшее внимание. Для макрорегионов предусмотрена только схема социально-экономического развития с целью обеспечения согласованного межрегионального экономического взаимодействия, не менее важным является согласование пространственной организации расселения, развития межрегиональной инфраструктуры.

В качестве ключевого механизма развития экономики страны и расселения в проекте СПРР принято создание новой магистральной сети. В указе Президента РФ от 7 мая 2018 года № 204 «0 рациональных целях и стратегических задачах РФ на период до 2024 года» правительству РФ поручено разработать с участием органов государственной власти, субъектов РФ и утвердить до 1 октября 2018 года комплексный план модернизации и расширения магистральной инфраструктуры, предусматривающий реализацию до 2024 года. Следует отметить, что при этом необходимо решать проблему высоких тарифов. В проекте отмечается, что одним из важнейших результатов развития транспортной инфраструктуры также станет вовлечение в радиус транспортной доступности крупнейших и крупных городских агломераций, городских округов и муниципальных районов, в которых проживают до 7 млн человек. Можно предположить, что это приведёт к дальнейшему усилению центростремительных потоков, нагрузок на ядра агломераций и, как следствие, - повышению транспортной усталости населения, ухудшению экологической ситуации. Напротив, появление новых центров экономического роста должно способствовать более равномерному распределению пассажиропотоков и снижению диспропорций в развитии территорий. Развитие магистральной сети не решит одну из серьезнейших проблем сельского расселения - бездорожье. Создание благоустроенных дорог в сельской местности требует государственной поддержки.

В проекте СПРР не затронута актуальная задача, для решения которой необходимо разработать соответствующие механизмы. В условиях отраслевого планирования возникает конфликт отраслевых интересов в части использования территорий, который выявляется при разработке региональных схем расселения, но не может быть решён на региональном уровне. Так, при проектировании схемы территориального планирования Алтайского края выяснилось, что для территорий предгорных районов разработан ряд отраслевых схем: развитие туризма, горнорудной промышленности, сельского хозяйства, здесь же задействованы интересы Роскосмоса (сюда возможно падение третьих ступень ракет). В природно-климатическом плане эта зона наиболее благоприятна для расселения населения. По экологическим критериям перечисленные функции использования территории несовместимы. Их присутствие в рамках одно и той же зоны создаёт некомфортные условия для развития отраслей, крайне ухудшает качество среды проживания населения. Нет инстанции, которая занимается разрешением отраслевых конфликтов федерального уровня в использовании территории. Назрела необходимость создания межведомственного органа по вопросам стратегического планирования при президенте или при правительстве, либо придание этих функций одному из существующих органов.

Другим предусмотренным проектом СПРР механизмом совершенствования расселения, является разработка ком- 
плексного проекта развития городов и сельских территорий. Суть этого проекта не расшифровывается. Необходимо напомнить, что Президент РФ В.В. Путин в послании Федеральному собранию 12 декабря 2013 года отметил, что на первый план выходит задача «закрепления людей на селе, формирование современной комфортной инфраструктуры в сельских территориях». Повышение качества жизни и уровня образования сельского населения рассматриваются как необходимая предпосылка увеличения объёмов выпуска продукции сельскохозяйственных предприятий [15]. Однако, несмотря на наличие ФЦП «Устойчивое развитие сельских территорий на 2014-2017 годы и на период до 2020 года», отток населения из сельской местности продолжается. По данным опросов Всероссийского НИИ экономики сельского хозяйства, около $30 \%$ сельских жителей, в том числе $50 \%$ молодёжи, намереваются уехать из родного села [16].

Комплексная программа развития городов - не новый инструмент. Она предусматривалась для реализации Генеральной схемы расселения СССР, но не получила развития. В этой связи возникает вопрос, в какой мере использование ранее применяемых, но не обеспечивших получение необходимых результатов механизмов государственного регулирования расселения сможет на этот раз преломить существующие негативные тенденции. Проведённый анализ позволяет прийти к выводу - ожидаемая результативность стратегии в плане создания предпосылок для решения актуальных проблем расселения - крайне низкая.

\section{Лuтература}

1. Сарварова, Э.Р. Городские агломерации и системы расселения: новые перспективы и барьеры развития / Э.Р. Сарварова, М.С. Гусева // Современные наукоёмкие технологии. - 2014. - № 7 (часть 1). - С. 79-81.

2. Фаттахов, Р.Ф. Городское расселение в России за 50 лет: оценка тенденций и перспектив / Р.Ф. Фаттахов, М.Н. Низамутдинов // Экономика и математические методы. 2014. - Том 50. - № 2. - С. 24-34.

3. Контрольно-надзорная деятельность в формировании новой эколого-экономической политики [Электронный ресурс] // Третий Невский конгресс. 14-15 мая 2010 г. - Режим доступа: http://82.rpn.gov.ru/sites/all/files/documents/ doklady/nevsky_doclad_11052010.doc (дата обращения 5.11.2018).

4. Шацкая И.В. От государственного стратегического планирования к стратегическому управлению / И.В. Шацкая // Российское предпринимательство. - 2014. - № 1 (247). - С. 50-57.

5. ВШЭ провела экспертизу проекта бюджетного прогноза России до 2034 года [Электронный ресурс] // Высшая школа экономики. Официальный сайт. - Режим доступа: https://www.hse. ru/expertise/news/197572762.html (дата обращения 5.11.2018).

6. Жуков М.А. Российская Арктика в 2016 году. Смена вектора управления Арктической зоной Российской Федерации [Электронный ресурс] / М.А. Жуков // Редкие zемли (The Rare
Earth Magazine). - Режим доступа: http://rareearth.ru/ru/ pub/20170201/02912.html (дата обращения 5.11.2018)

7. Drucker, J. Regional industrial structure and agglomeration economies: An analysis of productivity in three manufacturing industries [Электронный ресурс] / J. Drucker, E. Feser // Regional Science and Urban Economics. - 2012. - № 42. - P. 1-14. - Режим доступа: https://www.sciencedirect.com/science/ article/pii/S0166046211000573 (дата обращения 10.10.2018).

8. Роль первой генеральной схемы развития и размещения производительных сил [Электронный ресурс] // Всеобщая история архитектуры СССР. В 12-ти томах. Том 12. Книга 1. Архитектура СССР. Под ред. Баранова Н.В. - М.: Стройиздат, 1966-1977. - Режим доступа: https://institutiones.com/ general/85-2008-06-12-12-49-44.htm.

9. Поросенков, Ю.В. Теоретические проблемы разработки региональных схем развития и размещения производительных сил [Электронный ресурс] / Ю.В. Поросенков. 0.Ю. Сушкова // Геоэкология. - 2016. - № 4.

10. Гарифуллин, И. «Что для России значит "14 макрорегионов"?» [Электронный ресурс] // Idel.Реалии. - Режим доступа: https://www.idelreal.org/a/29461665.html (дата обращения 5.11.2018).

11. Матвиенко, В. Стратегия пространственного развития имеет ключевое значение для России и её регионов [Электронный ресурс] / В.И. Матвиенко // Федеральное собрание РФ. Официальный сайт. 27 июня 2018. - Режим доступа: http://council.gov.ru/events/news/93888/ (дата обращения 5.11.2018).

12. Осипов, Е. Власти Москвы прогнозируют прирост [Электронный ресурс] // Проект развития Большой Москвы. 2018. 17 мая. - Режим доступа: https://rg.ru/2018/05/.../ oon-prognoziruet-rost-naseleniia-v-iuzhnyh-gorodah-rossii.ht.

13. Швецов, А.Н. «Точки роста» или «чёрные дыры»? (К вопросу об эффективности применения «зональных» инструментов госстимулирования экономической динамики территорий) / А.Н. Швецов / Российский экономический журнал. - 2016. - № 3. - С. 45-65.

14. Градостроительная доктрина Российской Федерации / Г.В. Есаулов И.Г. Лежава, В.Я. Любовный [и др.]; РАAСН. - М.: Экон-информ, 2014. - 30 с.

15. Доклад об устойчивом развитии сельских территорий Российской Федерации [Электронный ресурс] // Сайт Союза органического земледелия. - Режим доступа: http://sozrf. ru//wp-content/uploads/2014/04/Госсовет_21.04.2014.pdf (дата обращения 5.11.2018).

16. Васькин, В.Ф. Устойчивое развитие сельских территорий как фактор роста уровня жизни населения / В.Ф. Васькин, А.И. Потворов / Вестник Брянской сельскохозяйственной академии. - 2016. - № 1 (53). - С.64-68.

\section{Literatura}

1. Sarvarova, E.R. Gorodskie aglomeratsii i sistemy rasseleniya: novye perspektivy i bar'ery razvitiya / E.R. 
Sarvarova, M.S. Guseva // Sovremennye naukoemkie tehnologii. - 2014. - № 7 (chast' 1). - S. 79-81.

2. Fattahov, R.F. Gorodskoe rasselenie v Rossii za 50 let: otsenka tendentsij i perspektiv / R.F. Fattahov, M.N. Nizamutdinov // Ekonomika i matematicheskie metody. - 2014. - Tom 50. - № 2. - S. 24-34.

3. Kontrol'no-nadzornaya deyatel'nost' v formirovanii novoj ekologo-ekonomicheskoj politiki [Elektronnyj resurs] // Tretij Nevskij kongress. 14-15 maya 2010 g. - Rezhim dostupa: http://82.rpn.gov.ru/sites/all/files/documents/doklady/ nevsky_doclad_11052010.doc (data obrashheniya 5.11.2018).

4. Shatskaya I.V. Ot gosudarstvennogo strategicheskogo planirovaniya k strategicheskomu upravleniyu / I.V. SHatskaya //Rossijskoe predprinimatel'stvo. - 2014. - № 1 (247). - S. 50-57.

5. VShE provela ekspertizu proekta byudzhetnogo prognoza Rossii do 2034 goda [Elektronnyj resurs] // Vysshaya shkola ekonomiki. Ofitsial'nyj sajt. - Rezhim dostupa: https://www. hse.ru/expertise/news/197572762.html (data obrashheniya 5.11.2018).

6. Zhukov M.A. Rossijskaya Arktika v 2016 godu. Smena vektora upravleniya Arkticheskoj zonoj Rossijskoj Federatsii [Elektronnyj resurs] / M.A. ZHukov // Redkie zemli (The Rare Earth Magazine). - Rezhim dostupa: http://rareearth.ru/ru/ pub/20170201/02912.html (data obrashheniya 5.11.2018)

7. Drucker, J. Regional industrial structure and agglomeration economies: An analysis of productivity in three manufacturing industries [Elektronnyj resurs] / J. Drucker, E. Feser // Regional Science and Urban Economics. - 2012. - № 42. - R. 1-14. - Rezhim dostupa: https://www.sciencedirect.com/science/ article/pii/S0166046211000573 (data obrashheniya 10.10.2018).

8. Rol' pervoj general'noj skhemy razvitiya i razmeshheniya proizvoditel'nyh sil [Elektronnyj resurs] // Vseobshhaya istoriya arhitektury SSSR. V 12-ti tomah. Tom 12. Kniga 1. Arhitektura SSSR. Pod red. Baranova N.V. - M.: Strojizdat, 1966-1977. - Rezhim dostupa: https://institutiones.com/ general/85-2008-06-12-12-49-44.htm.
9. Porosenkov, Yu.V. Teoreticheskie problemy razrabotki regional'nyh skhem razvitiya i razmeshheniya proizvoditel'nyh sil [Elektronnyj resurs] / Yu.V. Porosenkov. 0.Yu. Sushkova // Geoekologiya. - 2016. - № 4.

10. Garifullin, I. "Chto dlya Rossii znachit “ 14 makroregionov"?» [Elektronnyj resurs] // Idel.Realii. - Rezhim dostupa: https://www.idelreal.org/a/29461665.html (data obrashheniya 5.11.2018).

11. Matvienko, V. Strategiya prostranstvennogo razvitiya imeet klyuchevoe znachenie dlya Rossii i ee regionov [Elektronnyj resurs] / V.I. Matvienko // Federal'noe sobranie RF. Ofitsial'nyj sajt. 27 iyunya 2018. - Rezhim dostupa: http:// council.gov.ru/events/news/93888/ (data obrashheniya 5.11.2018).

12. Osipov, E. Vlasti Moskvy prognoziruyut prirost [Elektronnyj resurs] // proekt razvitiya Bol'shoj Moskvy. 2018. 17 maya. - Rezhim dostupa: https://rg.ru/2018/05/.../oonprognoziruet-rost-naseleniia-v-iuzhnyh-gorodah-rossii.ht.

13. Shvetsov, A.N. «Tochki rosta» ili «chernye dyry»? (K voprosu ob effektivnosti primeneniya «zonal'nyh» instrumentov gosstimulirovaniya ekonomicheskoj dinamiki territorij) / A.N. Shvetsov / Rossijskij ekonomicheskij zhurnal. - 2016. - № 3. - S. 45-65.

14. Gradostroitel'naya doktrina Rossijskoj Federatsii / G.V. Esaulov I.G. Lezhava, V.Ya. Lyubovnyj [i dr.]; RAASN. - M.: Ekoninform, 2014. - $30 \mathrm{~s}$.

15. Doklad ob ustojchivom razvitii sel'skih territorij Rossijskoj Federatsii [Elektronnyj resurs] // Sajt Soyuza organicheskogo zemledeliya. - Rezhim dostupa: http://sozrf. ru//wp-content/uploads/2014/04/Gossovet_21.04.2014.pdf (data obrashheniya 5.11.2018).

16. Vas'kin, V.F. Ustojchivoe razvitie sel'skih territorij kak faktor rosta urovnya zhizni naseleniya / V.F. Vas'kin, A.I. Potvorov / Vestnik Bryanskoj sel'skohozyajstvennoj akademii. - 2016. - № 1 (53). - S.64-68.

Герцберг Лора Яковлевна (Москва). Доктор технических наук, член-корреспондент РААСН. Главный научный сотрудник ФГБУ «Центральный научно-исследовательский и проектный институт Министерства строительства и жилищно-коммунального хозяйства» (119331 , Москва, просп. Вернадского, 29. ЦНИИП Минстроя России). Автор более 150 научных работ и публикаций, автор и соавтор более 40 проектов. Сфера научных интересов: экономика градостроительства, территориальное планирование, инфраструктура городского земельного рынка. Тел.: +7 (915) 327-99-59. E-mail: Igertz24@mail.ru.

Gertsberg Lora Yakovlevna (Moscow). Doctor of technical sciences, corresponding member of the RAACS. Chief researcher of the FGBU "The Central Institute for Research and Design of the Ministry of Construction and Housing and Communal Services of the Russian Federation" (119331, Moscow, Vernadskogo ave., 29. TsNIIP Minstroy of Russia). The author of more than 150 scientific works and publications, author and coauthor of more than 40 projects. Scientific interests: economy of urban planning, territorial planning, infrastructure of urbanland market. Tel.: +7 (915) 327-99-59. E-mail: lgertz24@mail.ru. 